\title{
State of Geriatric Mental Health in India
}

\author{
Om Prakash • Prerna Kukreti
}

Published online: 20 December 2012

(C) Springer Science+Business Media New York 2012

\begin{abstract}
The elderly population of India is steadily increasing. Most common psychiatric illnesses in the Indian elderly population are depression, dementia and anxiety disorders. Resources available to cater to the needs of elderly in the country are government and private psychiatric hospitals, non-governmental organisations and the family as caregivers. Lack of awareness, inadequate training opportunities; inequitable distribution of health resources and virtual absence of chronic care disease models are the challenges that confound the future of geriatric psychiatry in India. Government policies providing social benefits to the elderly population are in place but coverage is inadequate. For addressing geriatric mental health issues, the need of the hour is to increase awareness, capacity building, strengthening training and research activities, developing community based rehabilitation programmes and developing a holistic primary health care system.
\end{abstract}

Keywords India $\cdot$ Aged $\cdot$ Demography $\cdot$ Disease $\cdot$ Mental health $\cdot$ Mental disorders $\cdot$ Morbidity $\cdot$ Prevalence studies . Depression $\cdot$ Dementia $\cdot$ Health attitudes $\cdot$ Knowledge and practice $\cdot$ Health resources $\cdot$ Health services for the aged . Health system agencies · Manpower · Family systems · Caregivers $\cdot$ Utilization $\cdot$ Health services $\cdot$ Government health policies $\cdot$ Health programs $\cdot$ Awareness $\cdot$ Mental health $\cdot$ Home based care $\cdot$ Rehabilitation .

Research $\cdot$ Community

O. Prakash $(\bowtie) \cdot$ P. Kukreti

Department of Psychiatry, Institute of Human Behaviour \& allied

Sciences (IHBAS), Dilshad Garden,

New Delhi, India 110095

e-mail: drjhirwalop@yahoo.co.in

O. Prakash

e-mail: drjhirwalop@hotmail.com

\section{India is Greying}

India is a republic consisting of twenty-eight states and seven union territories. As of 2011, with an estimated population of 1.21 billion, India is the world's second most populated country after China [1]. It accounted for more than 17 per cent of the world's population in 2011 according to the estimates prepared by the United Nations [2].

India is in a process of demographic transition. There is a downward shift from a high mortality/high fertility scenario to a low mortality/low fertility scenario. The expectancy of life at birth has almost doubled from 32 years in 1947 to 63.4 years in 2011 [3]. The elderly population accounted for $7.1 \%$ of total population in 2001 and it is projected to increase its share to more than $10 \%$ by the year 2021 [4]. The demographic profile depicts that in the years 2000-2050, the overall population in India will grow by $55 \%$ whereas the aged population of 60 years and above will increase by $326 \%$ and those in the age group of $80+$ by $700 \%$ [5]. This has resulted in an increased proportion of older people in the total population, termed as the "greying of population".

The elderly population is facing a huge burden of communicable and non-communicable diseases. However, rapid changes in the family systems in India have made the elderly people more prone to psychological problems. Thus, there is a felt need to evolve programmes targeting geriatric mental health. The current paper analyses the issues related to geriatric mental health and the future roadmap for India.

\section{Characterization of Indian Elderly}

Socio-demographic Profile of the Elderly

According to India's Census (2011), it was observed that $75 \%$ of elderly persons were living in rural areas. Around 
$48.2 \%$ of elderly persons were females, out of whom $55 \%$ were widows. Almost eight out of ten older people in India live in rural areas. A total of $73 \%$ of elderly persons were illiterate and dependent primarily on agriculture. About $90 \%$ of the elderly were from the unorganized sector, i.e., they have no regular source of income. Two-thirds of them were reported to be living below the poverty line, i.e., $66 \%$ of older persons were in a vulnerable situation without adequate food, clothing, or shelter. The old-age dependency ratio increased from $10.9 \%$ in 1961 to $13.1 \%$ in 2001, as a whole. About 65 percent of the aged had to depend on others for their daily living [3].

\section{Attitudinal Barriers}

India is a multicultural, pluralistic society with enormous socioeconomic disparities. This variety on the one hand is exciting, stimulating much research into behaviour and mental health; on the other hand, it is a daunting task to provide care to the heterogeneous population with variable knowledge of attitude and practices. As per the prevailing socially sanctioned roles for elderly in India, most of the time symptoms of illness are disregarded both by patient and family as part of the "normal aging process" or something "not serious". Even if it is acknowledged as a problem, some choose to selfmedicate or use home remedies. Alternative healing practices, especially religious healing, are still the first resort for many. Those reaching to mental health care workers have to be contended with for the misconceptions about mental disorders and the stigma attached to them. Lack of awareness surrounding mental illness makes it more stigmatised. In India, financial constraint and poverty too is a big hurdle in developing countries for treatment seeking [6]. The challenge is to develop culturally sensitive services designed for a low income population and spreading more community awareness.

\section{Burden of Medical Disease Faced by the Elderly}

The elderly population is sandwiched by the dual burden of communicable and non-communicable diseases compounded by age related sensory impairments. According to the Government of India statistics (2006), the chronic illnesses in the elderly usually include rheumatism, hypertension, coronary heart disease, and cancer [7]. Cardiovascular disorders account for one-third of elderly mortality. Respiratory disorders account for $10 \%$ mortality while infections, including tuberculosis, account for another $10 \%$. Neoplasms account for $6 \%$ and accidents, poisoning, and violence constitute less than $4 \%$ of elderly mortality with more or less similar rates for nutritional, metabolic, gastrointestinal, and genito-urinary infections [8]. Hearing impairment was found to be the most common morbidity followed by visual impairment on a chronic morbidity profile in the elderly [9]. A higher number of morbidities was associated with greater disability and distress [10].

\section{Burden of Geriatric Mental Health in India: A Silent Epidemic}

The burden of mental disorders' morbidities is increasing in the Indian elderly due to ageing of the brain, problems associated with physical health, cerebral pathology and socio-economic factors such as breakdown of the family support systems, social isolation and decrease in economic independence [9]. Epidemiological data about this population is still scarce. Most of these studies are part of general population studies or hospital based or primary care geriatric patients' studies rather than community based. Dube (1970) reported the prevalence of mental illnesses in the elderly to be $2.23 \%$ [11], while Nandi and his co-workers (1975) found it as $33.3 \%$ in rural India [12]. Ramachandran and his colleagues (1979) found this prevalence as $35 \%$ [13]. Another research group led by Tiwari (2000) found it to be much higher in the geriatric group (43.32\%) as compared to $4.66 \%$ in the non-geriatric group [14].

The reported prevalence of geriatric psychiatric morbidity in the community varied from $8.9-61.2 \%$ [15]. The mental disorders frequently encountered in the Indian elderly include dementia and mood disorders, depression in particular. Other disorders include anxiety disorders, drug and alcohol abuse, delirium and psychosis [16-21]. Female sex, low education, being a widow/widower/divorcee, medical co-morbidities, poor socio-economic status and disability are all well-established factors playing significant roles in psychiatric illnesses among the elderly [13, 22, 23].

Studies from hospital clinics, community as well as old age homes found depression as the most common psychiatric disorder in the geriatric population with prevalence ranging from $22.2 \%$ to $55.2 \%$ of gero-psychiatric patients [13, 16, 24-26]. Suicide, especially due to depression, occurs more frequently in the elderly and adds to this problem [27]. But, depression is an often-missed diagnosis especially in the medical elderly patients. In one study, Prakash and his colleagues reported $23 \%$ of patients having depressive symptoms and $18 \%$ having a definite depressive disorder among geriatric clinic attendees. Surprisingly, none of the geriatric physicians even from a tertiary clinic setting had made a diagnosis of depression [28].

Dementia seems to be the next silent epidemic in the country. The prevalence of dementia in Indian studies has been shown to vary from $0.84 \%$ to $6.7 \%$ [29-32]. Diabetes, depression, hyperlipidaemia, urban living and lack of exercise are independent risk factors for dementia. Living in joint families and increased intake of polyunsaturated fats conferred protection against dementia [33]. The prevalence 
of anxiety disorders has been reported to range from $5.34 \%$ to $21.35 \%$ for gero-psychiatric patients $[34,35]$.

\section{Geriatric Mental Health Care System in India}

\section{Infrastructure}

India has four types of resources to address geriatric mental health issues: 1) state funded government psychiatric hospitals and nursing homes; 2) private psychiatric hospitals and nursing homes; 3 ) non-government organisations; and 4) the most important, informal sources- family as caregivers.

The country has limited numbers of mental health professionals, around 4000 psychiatrists catering to the 21 million geriatric populations in need of mental health services [36]. In terms of infrastructure, very few Indian hospitals have geriatric units and most elderly patients are treated in general medical/psychiatry wards. At present, most of the geriatric outpatient department (OPD) services are available at tertiary care hospitals in big cities. Public sector hospitals suffer from problems of inaccessibility, inequitable distribution, lack of staff, drugs and equipment while the private sector is largely unregulated with serious complaints regarding poor quality of care and unethical behaviour. The health insurance sector in India doesn't cover mental illnesses; otherwise too, in general, less than $20 \%$ of Indians have some form of health insurance [37].

Several indigenous systems of medicine also operate in India amidst the formal public and private systems and offer treatments which may be more accessible, affordable or acceptable to the rural elderly. However, a recent study suggests that graduates of indigenous medical programs often lack the clinical training required to utilize diagnostic tools, conduct basic procedures and handle primary care emergencies [38]. A large portion of the population is forced to bypass free public services to pay out-of-pocket in private institutions [39].

The focus of mental health care in India is still on tertiary care and acute management as opposed to developing primary care or rehabilitative services. Though new initiatives such as day care centres, old age residential homes, memory clinics, helplines, counselling and recreational facilities are being developed, most of them are urban based and concentrated mainly in southern part of India. Non-governmental organisations like Help Age India, the Age well Foundation and the Dignity Foundation too are actively contributing, but still efforts are far from reaching to the masses [40]. A study conducted to assess the unmet needs of the geriatric population in rural areas observed that as many as $46.3 \%$ of the study participants were unaware of the availability of any geriatric services near their residence and $96 \%$ had never used any geriatric welfare service. About $59 \%$ of them stated that the nearest government facility was 3 kilometres from their homes [41].

The silver lining of clouds surrounding meagre geriatric mental health resources available is undoubtedly the support of families, who irrespective of their financial status, deem it their responsibility to care for their elderly mentally ill relatives. In the current era of modernisation, globalization and eroding social values, there is an apparent weakening of joint family systems. The younger generation is searching for new identities and redefining new social roles within, as well as outside, the family. The changing economic structure has reduced the dependence of rural families on agriculture, which had provided strength to bonds between generations. The traditional sense of duty and obligation of the younger generation towards their older generation is being eroded. The Indian elderly generation is caught between the decline in traditional values on the one hand and the absence of an adequate social security system, on the other [42]. It has led to increased incidences of the elderly being abandoned as homeless by family members. State provided facilities for day care centres and respite care are scarce. There is a sheer absence of any home based rehabilitation measures or benefits accorded by the state to families to address caregiver burdens [43]. In terms of manpower training and research, there are few opportunities for geriatric knowledge building and formal training in India. Geriatric medicine training is offered only in a college in Chennai. Geriatric psychiatry is a neglected branch. The Medical Council of India, the medical education regulatory body, offers this super speciality training only in Lucknow and Bangalore. Of these handful, psychiatrists available too, but the brain drain of psychiatrists towards the West is not an uncommon problem. Advocacy and research activities are only left to a few organisations like the Indian Association for Geriatric Mental Health, Geriatric Society of India, Indian Academy of Geriatrics and the Association of Gerontology [43]. The efforts in place for geriatric care are noteworthy but highly inadequate.

\section{Health Services Utilization}

Healthcare utilization is irregular across the country. It is found to be greater among older adults with higher levels of education, those living in urban areas and among those seeking treatment for communicable rather than noncommunicable diseases. Non-compliance with treatment plans and drug regimens is also an impediment to managing the health of this population, resulting in an estimated $8 \%$ of hospital admissions; the most commonly cited reasons for non-compliance include cost, inadequate instruction, and a switch to non-conventional treatment. The influence of cost constraints on decisions to seek or continue treatment, as noted above, highlights the fundamental role poverty plays in shaping the health of India's aging population [6]. 


\section{Role of Government Policies: More Carrots, Less Sticks}

The well-being of senior citizens is mandated in the Constitution of India under Article 41: "The state shall, within the limits of its economic capacity and development, make effective provision for securing the right to public assistance in cases of old age" [40]. However, health is not the priority for the government and, of all the mental health and geriatric sectors, it is the least appealing, non-productive negligent bunch of all when it comes to budgetary allocation [44]. Though there are Government and social policies for the elderly in India are in place and include old age pensions, the National Policy for Older Persons (1999), the National Initiative on Care for the Elderly (2004), and the Maintenance and Welfare of Parents and Senior Citizens Act (2007) [45].

The most recent effort is the National Programme for the Health Care of the Elderly (NPHCE), released in early 2011. Social security provisions for pension, income tax benefits, provident fund gratuity, and medical assistance have been strengthened. Focus is shifting more on capacity building by: (1) expanding infrastructure to include Regional Geriatric Centres in district hospitals and opening community-based geriatric clinics; (2) establishing specialized geriatric training programs and research institutes; and (3) utilizing mass media to educate the public. The program also aims to promote strong inter-organizational linkages and referral mechanisms as well as training and support for informal caregivers. The program is being implemented in phases beginning with 100 districts in 21 of India's 28 states [46].

Despite the policies being in place, the grounded reality is that they have not been implemented in their true sense. Still most of the policies talk about social benefits in general for the elderly than showing concern for geriatric mental health. Policy makers should not forget that caregivers and families are indeed a rich resource, which should be utilised, but ensuring at the same time that they receive adequate support from health professionals, and the community [44].

\section{Recommendations: A Way Ahead}

In spite of the growing requirement for mental health services for older persons, there is substantial unmet need. Since the elderly segment doesn't actively contribute to the productive population, so then it often fails to receive its due attention from policy makers. What is often forgotten is that, they make important contributions to the society not only via the formal workforce (primarily in agriculture), but also in raising grandchildren, volunteering, caring for the sick, resolving conflict and offering counsel, and translating experience, culture, and religious heritage. If in a low resource setting, improving lifespan and decreasing mortality was an achievement of the 20th century, then ensuring good quality geriatric care is going to be the challenge of 21 st century. There is an urgent need for developing appropriate and effective health services directed towards this population.

Increasing Awareness

An important prerequisite to improving care for older persons is to create a climate that fosters such improvement. Awareness needs to be spread regarding mental health problems, specific needs of the geriatric population and availability of services available in this regard. The existing framework should allow for positive engagement between clinicians, researchers, caregivers and elderly people with mental illness.

\section{Training \& Manpower Development}

There is a felt need to expand the teaching curriculum across all the disciplines to include geriatric care components including general physicians, psychiatrists, psychologists, psychiatric nursing and psychiatric social work. Also, there is a need to increase the seats in geriatric medicine speciality and geriatric psychiatry super speciality courses and developing programmes for sensitising general physicians and health workers for screening and appropriate referral. An Indian Council of Medical Research (ICMR) task force project "Health Care of the Rural Aged", conducted in the Primary Health Centre area near Madurai found this strategy to be beneficial [47]. There is an urgent need to establish geriatric centres of excellence catering to a multidisciplinary approach.

\section{Home Based Care Programmes}

In the current scenario where training a health professional is a time and resource-consuming affair, countries like India can develop adequate training programmes for the major current task force in the service of the elderly in country, i.e., family members. Supporting, educating and advising family caregivers is a cost effective strategy for developing countries as it requires only one tenth of resources as invested in residential care. A randomised controlled trial for home based care programme from Goa has shown promising results [48].

\section{Rehabilitation Services}

There is an urgent need of a paradigm shift in the care model beyond the current preoccupation with simple curative interventions to encompass long-term support and chronic disease management. Adequate services for establishing continuity of care beyond hospitals in the community including day care centres, respite care facilities, half way homes, and old age homes needs to be developed. 


\section{Need for Research}

The paucity of population-based research calls for more good quality epidemiological and health services research which will help to generate awareness, shape health and social policy and encourage the development of better services for patients and their caregivers.

\section{Conclusion}

Geriatric mental health is a neglected issue with poor sensitivity amongst patients, caregivers and administrators. Staunch efforts should be made for making treatment accessible, available and affordable in community. There is a need to raise awareness in public and other professionals about unmet needs of geriatric mental health, developing adequate human resources and strengthening inter-sectorial collaboration. There is an urgent need to implement national policies, programmes and legislation targeting geriatric mental health and promoting advocacy and empowerment.

Disclosure No potential conflicts of interest relevant to this article were reported.

\section{Conflict of interest None.}

\section{References}

1. Chandramouli C. Census of India 2011 - A story of Innovations. Press Information Bureau, Government of India. http://www.censusindia.gov.in. Accessed on 15 November 2012.

2. United Nations. World Urbanization Prospects: The 2011 Revision Highlights. United Nations, Department of Economic and Social Affairs/Population Division. United Nations, New York. http:// esa.un.org/unup/pdf/WUP2011_Highlights.pdf. Accessed on 15 November 2012.

3. Government of India. Situation analysis of the elderly in India. Central Statistics Office, Ministry of Statistics \& Programme Implementation, Government of India, June 2011.

4. Irudaya Rajan S. In: Dey AB, editor. Ageing in India, situational analysis and planning for the future. New Delhi: Rakmo Press; 2003.

5. United Nations. World population ageing: 1950-2050. New York: Department of Economic and Social Affairs, Population Division, United Nations; 2002.

6. Agrawal G, Arokiasamy P. Morbidity prevalence and health care utilization among older adults in India. J Appl Gerontol. 2010;29(2):155-79.

7. Government of India. Morbidity, health care and the condition of the aged. National Sample Survey Organization 60th round (January-June 2004); 2006.

8. Khandelwal SK. Mental health of older people. In: Dey AB, editor. Ageing in India. Situational analysis and planning for the future. New Delhi: Rakmo Press; 2003.

9. Guha R. Morbidity related epidemiological determinants in Indian aged - an overview. In: Ramachandran CR, Shah B, editors. Public health implications of ageing in India. New Delhi: Indian Council of Medical Research; 1994.

10. Joshi K, Kumar R, Avasthi A. Morbidity profile and its relationship with disability and psychological distress among elderly people in Northern India. Int J Epidemiol. 2003;32(6):978-87.

11. Dube KC. A Study of prevalence and biosocial variation in mental illness in a rural and urban community in Uttar Pradesh, India. Acta Psychiatr Scand. 1970;48:18.

12. Nandi DN, Ajmani S, Ganguli A, Banerjee G, Boral GC, Ghosh A, Sankar S. Psychiatric disorders in a village community in West Bengal. Indian J Psychiatry. 1975;17:87.

13. Ramchandran, Menon SM, Ramamurthy B. Psychiatric disorders in subjects over fifty. Indian J Psychiatry. 1979;22:193-8.

14. Tiwari SC. Geriatric psychiatric morbidity in rural northern India: Implications for the future. Int Psychogeriatr. 2000;12:35-48.

15. Shaji KS, Jithu VP, Jyothi KS. Indian research on aging and dementia. Indian J Psychiatry. 2010;52:148-52.

16. Seby K, Chaudhury S, Chakraborty R. Prevalence of psychiatric and physical morbidity in an urban geriatric population. Indian $\mathrm{J}$ Psychiatry. 2011;53:121-7.

17. Prakash O, Kumar CN, Shivakumar PT, Bharath S, Varghese M. Clinical presentation of mania compared with depression: data from a geriatric clinic in India. Int Psychogeriatr. 2009;21(4):764-7.

18. Rao VA, Madhavan T. Geropsychiatric morbidity survey in a semi urban area near Madurai. Indian J Psychiatry. 1982;24:258-67.

19. Sood A, Singh P, Gargi PD. Psychiatric morbidity in nonpsychiatric geriatric inpatients. Indian J Psychiatry. 2006;48:56-61.

20. Singh GP, Chavan BS, Arun P, Lobraj SA. Geriatric out-patients with psychiatric illnesses in a teaching hospital setting - a retrospective study. Indian J Psychiatry. 2004;46(2):140-3.

21. Prakash O, Gupta LN, Singh VB, Singhal AK, Verma KK. Profile of psychiatric disorders and life events in medically ill elderly: experiences from geriatric clinic in Northern India. Int J Geriatr Psychiatry. 2007;22(11):1101-5.

22. Harris T, Cook DG, Victor C, Rink E, Mann AH, Shah S, Dewilde S, Beighton C. Predictors of depressive symptomsin older peoplea survey of two general practice populations. Age and Ageing. 2003;32(5):510-8.

23. Guha S, Valdiya PS. Psychiatric morbidity amongst the inmates of old age home. Indian J Psychiatry. 2000;42:S44.

24. Tiple P, Sharma SN, Srivastava AS. Psychiatric morbidity in geriatric people. Indian J Psychiatry. 2006;48(2):88-94.

25. Rajkumar AP, Thangadurai P, Senthilkumar P, Gayathri K, Prince M, Jacob KS. Nature, prevalence and factors associated with depression among the elderly in a rural south Indian community. Int Psychogeriatr. 2009;21(2):372-8.

26. Sureshkumar R, Bharath S, Jain S, Prakash O, Purushottam M, Thennarasu K, Mukherjee O, Sivakumar PT, Varghese M. ApoE4 and late onset depression in Indian population. J Affect Disord. 2012;136(3):244-8.

27. Rao AV, Madhavan T. Depression and suicide behaviour in the aged. Indian J Psychiatry. 1983;25:251-9.

28. Prakash O, Gupta LN, Singh VB, Nagrajarao N. Applicability of 15 -item geriatric depression scale to detect depression in elderly medical outpatients. Asian J Psychiatry. 2009;2(2):63-5.

29. Shaji S, Bose S, Varghese A. Prevalence of dementia in an urban population in Kerala, India. British J Psychiatry. 2005; 186:136-40.

30. Vas CJ, Pinto C, Panikker D, Noronha S, Deshpande N, Kulkarni L, et al. Prevalence of dementia in an urban Indian Population. Int Psychogeriatr. 2001;13:439-50.

31. Prasad K, Gupta H, Bharath S, Prakash O, Sivakumar PT, Kumar $\mathrm{CN}$, Varghese M. Clinical practice with antidementia and antipsychotic drugs: audit from a geriatric clinic in India. Indian J Psychiatry. 2009;51(4):272-5. 
32. Prince MJ. The 10/66 dementia research group - 10 years on. Indian J Psychiatry. 2009;51 Suppl 1:S8-15.

33. Tripathi M, Vibha D, Gupta P, Bhatia R, Srivastava MV, Vivekanandhan S, Bhushan Singh M, Prasad K, Dergalust S, Mendez MF. Risk factors of dementia in North India: a casecontrol study. Aging Ment Health. 2012;16(2):228-35.

34. Tiwari SC, Srivastava S. Geropsychiatric morbidity in rural Uttar Pradesh. Indian J Psychiatry. 1998;40:266-73.

35. Prakash O, Rajkumar RP. Anxiety disorders in late-life: a clinical overview. Indian J Private Psychiatry. 2009;3:13-8.

36. Thirunavukarasu M, Thirunavukarasu P. Training and National deficit of psychiatrists in India - a critical analysis. Indian J Psychiatry. 2010;52:83-8.

37. Biswas S. Implication of population and aging. In Public health implications of aging in India: Ramachandra C, Shah B, editors. Indian Council of Medical Research; 1994. pp.22-35.

38. Patwardhan K, Gehlot S, Singh G, Rathore HC. The ayurveda education in India: how well are the graduates exposed to basic clinical skills? Evid Based Complement Alternat Med. 2011;2011:197391.

39. Shaji KS, Jotheeswaran AT, Girish N, Bharath B, Dias A, Pattabiraman M, Varghese M. The dementia India Report 2010: prevalence, impact, costs and services for dementia: executive summary. New Delhi: Alzheimer's \& Related Disorders Society of India; 2010.
40. Krishnaswamy B, Sein U, Munodawafa D, Varghese C, Venkataraman K, Anand K. Ageing in India. Ageing Int. 2008;32(4):258-68.

41. Goel PK, Garg SK, Singh JV, Bhatnagar M, Chopra H, Bajpai SK. Unmet needs of the elderly in a rural population of Meerut. Indian J Community Med. 1999;28:165-6.

42. Bhat AK, Raj D. Ageing in India: drifting intergenerational relations, challenges and options. Ageing Soc. 2001;21(5):621-40.

43. Gupta R. Systems perspective: understanding care giving of the elderly in India. Health Care Women Int. 2009;30(12):1040-54.

44. Government of India. National health accounts India 2004-05. http://www.whoindia.org/LinkFiles/Health_Finance_National_ Health_Accounts 2004-05.pdf. Accessed on 14 November 2012.

45. Gokhale S. Towards a policy for aging in India. J Aging Soc Policy. 2003;15:213-34.

46. Government of India. National programme for the healthcare of the elderly: an approach towards active and healthy ageing. http:// www.jkhealth.org/notifications/bal456.pdf. Accessed on 14 November 2012.

47. Rao VA. Health care of rural aged. New Delhi: Indian Council of Medical Research; 1984.

48. Dias A, Dewey ME, D'Souza J, Dhume R, Motghare DD, et al. The effectiveness of a home care program for supporting caregivers of persons with dementia in developing countries: a randomised controlled trial from Goa, India. PLoS ONE. 2008;3(6):e2333. 